\title{
A Review on the Phytochemical and Anti-Hyperglycaemic Properties of the Fractionated Anacardium Occidentale L Leaves, Seeds and Stem Barks Extracts
}

\author{
Omojate C Godstime $^{1}$, Felix O Enwa ${ }^{1 *}$, Clement O Anie ${ }^{1}$, Oghenejobo Micheal ${ }^{1}$ \\ And Akpotu Mark ${ }^{2}$ \\ ${ }^{I}$ Department of Pharmaceutical Microbiology, Faculty of Pharmacy, Delta State University, Abraka, Nigeria. \\ ${ }^{2}$ Department of Pharmaceutical Microbiology and Biotechnology, Faculty of Pharmacy, Nnamdi Azikiwe \\ University, Awka, Nigeria.
}

\begin{abstract}
Despite considerable progress in the management of dysglycaemia by synthetic drugs, the search for improved and safe natural antidiabetics is ongoing, since the plant kingdom offers a wide range of oral hypoglycaemics.The phytochemical profile and the antihyperglycaemic properties of the various fractions of Anacardiumoccidentale L leaves, seeds as well as the stem barks extracts, on normoglycaemic animal models were reviewed.The extractants were tested for the presence of elementary phytochemicals following standard procedures.The phytochemical analysis of A. occidentaleextracts revealed the presence of a variety of rich secondary metabolites such as tannins, terpenoids, alkaloids, flavonoids, phenols, steroids, glycosides and volatile oils. In the assay, various concentrations of the leaves, seeds and stem bark extracts $25 \mathrm{ug} / \mathrm{ml}, 50 \mathrm{ug} / \mathrm{ml}$ and $100 \mathrm{ug} / \mathrm{ml}$, were prepared. Also, $50 \mathrm{ug} / \mathrm{ml}$ solution of anacardic acid, the active antidiabetic principle in cashew extract was prepared. The solutions were administered to the mouse and rat cell models, and incubated for 18hours, after which the glucose uptake was measured. In the case of the seeds extract, only $100 \mathrm{ug} / \mathrm{ml}$ had a significant effect. Glucose uptake was significantly elevated in cells incubated with high dose of the extract and insulin, as compared with either the insulin or the extracts alone. The results obtained from this research that the leaves, seeds as well as the stem barks extracts of A. occidentale could be a lead candidate for the synthesis of potent antidiabetics or a nutraceutical for the management of dysglycaemia, which had posed a new threat to the global health security.
\end{abstract}

Keywords- Dysglycaemia, Insulinopenia, Phytochemicals, Pancreatectomize.

\section{INTRODUCTION}

There is an escalating incidence of diabetes mellitus with a major impact on the population of developing countries possibly due to absence of cost-effective chemotherapeutic interventions for diabetes mellitus. Many plant species have been reported to display hypoglycaemic effects, but only few of them have been investigated, and the World Health Organization advocates that this area warrants attention. The search for anti-diabetic agents has been focused on plants because of their availability, efficacy, affordability, and probable minimal untoward effects.

Tradomedicinal plants with various doses of bioactive principles have been used since time immemorial, to treat an array of human diseases such as dysglycaemia. Some herbal preparations contain important micronutrients that have favourable effects on glycaemic control and body weight, hence the body mass index. The beneficial multiple activities like altering carbohydrate digestion and absorptions, beta cell stimulation, mimicking the actions of the insulin, inhibiting mopping up reactive oxygen species present in medicinal plants account for their anti-diabetic effects [1].

The plant kingdom offers a wide field to look for oral hypoglycaemic agents that could be used in the management of diabetes mellitus without unpleasant side effects such as Lipoatrophy seen with subcutaneous insulin therapy as well as hypoglycaemic episodes. A. occidentale is a member of the Anacardiaceae family and its English name derives from the Portuguese name for the fruit of the cashew tree, caju, which in turn derives from the indigenous Tupi name, acajú. It is now widely grown in tropical climates for its cashew nuts and cashew apples. A.occidentale is native to Brazil, the Portuguese, Goa, India, Southeast, Asia and Africa [2]. The plant contains alpha-linolenic acid, anacardic acid, arginine, ascorbic acid, benzaldehyde, beta-carotene, beta-sitosterol, calcium, gallic acid, palmitic acid, oleic acid, riboflavin, salicylic acid, selenium, tocopherol, vanadium and zinc [3].Initially, the plant was planted in India to reduce erosin but today, it is extensively used locally in treating diabetes mellitus, dyspepsia, impotence, diarrhoea, urinary disorders, veneral diseases, Leishmaniasis and Syphilis - related skin disorders. The antimicrobial activities of A. occidentaleextracts have been confirmed. Its fruits were shown to exhibit significant antibacterial activity against Helicobacter pylori that is commonly implicated in acute gastritis and stomach ulcers [4]. It has been found to also possess anti-viral, anti-fungal, anti-bacterial activities [5]. 
Diabetes mellitus is characterized by loss of glucose homeostasis, altered metabolism of lipids and proteins, and increased risk of atherosclerosis, coronary heart disease, renal failure, nerve damage, and blindness [6]. Type II diabetes mellitus accounts for approximately $85 \%$ of all cases of diabetes mellitus and is an important risk factor for cardiovascular morbidity and mortality [7]. Treatment with blood lipid-lowering agents has been shown to reduce micro- and macro vascular complications of the coronary artery and cerebral vascular diseases in type 2 diabetic patients.

Diabetes mellitus is a syndrome characterized by disordered metabolism and inappropriately high blood sugar (hyperglycaemia) resulting from either low level or resistance to insulin. Insulin is produced by the beta cells of the endocrine part of the Pancreas. These cells are sensitive to cytotoxic action of Alloxan and Streptozotocin, which induce experimental diabetes mellitus in animals.

Although the pathogenesis of diabetes mellitus is multifactorial and necessitates multi-modal therapeutic approach, the use of nutraceutical therapy is a cornerstone in the management of diabetes. Elevated blood glucose (hyperglycaemia) per se does not elicit diabetic complications. It is rather the detrimental effect of glucose toxicity due to chronic hyperglycaemia, which is mediated and complicated through oxidative stress [1]. The pancreas has a relatively weak intrinsic defence system against oxidative stress and therefore the defence needs to be actuated extrinsicallywith the use of adjuvant nutraceutical therapy to combat the chronic dysglycaemia which had posed a new threat to the global health security.

Studies on the antihyperglycaemic properties of this plant across the globe have been documented [8] but there is no significant evidence to buttress the hypoglycaemic effect of the seeds, leaves and stem bark extracts of $A$. occidentalegrown in Nigeria. Hence, it is the purpose of the present study to ascertain the scientific basis for the use of $A$. occidentale extracts in the management of dysglycaemia by investigating the phytochemical profile and hypoglycaemic activities on normoglycemic animal models.

\section{Review of The Hypoglycaemic Activities of the Various Extracts of Anacardiumoccidentale(Cashew)}

Several hypoglycaemic activities of Anacardiumoccidentale extracts have been documented. In a study, cashew seeds extract was investigated for anti-diabetic activities. In the in vitro assay using mouse and rat liver models, it was found that the glucose uptake stimulatory effect occurred at elevated doses. Other plant part extracts were tested but the seeds extract had the most significant stimulatory effect on glucose uptake, suggesting that the cashew seeds extract contain bioactive principles with potent anti-diabetic properties. With regards to insulin response, the impact of cashew plant extracts on cells that respond to insulin was evaluated. Cashew extracts have traditionally been thought to elicit anti-inflammatory properties, hence, could help counter hyperglycaemia and to prevent insulin resistance. The phytochemical tests revealed the presence of carbohydrates, saponins, glycosides, proteins, alkaloids, tannins, phenolics and flavonoids in the extracts.In the assay, various concentrations of the seeds extract $25 \mathrm{ug} / \mathrm{ml}, 50 \mathrm{ug} / \mathrm{ml}$ and $100 \mathrm{ug} / \mathrm{ml}$, were prepared. Also, $50 \mathrm{ug} / \mathrm{ml}$ solution of anacardic acid, the active antidiabetic principle in cashew extract was prepared. The solutions were administered to the mouse and rat cell models, and incubated for 18hours, after which the glucose uptake was measured. The results revealed that both the cashew seeds extract and anacardic acid stimulated cellular glucose uptake. In the case of the seeds extract, only $100 \mathrm{ug} / \mathrm{ml}$ had a significant effect. Glucose uptake was significantly elevated in cells incubated with high dose of the seeds extract and insulin, as compared with either the seeds extract or insulin alone. Also, similar results were obtained with anacardic acid plus insulin but there was no such synergistic action at lower concentrations of the seeds extract. Although the results obtained from this study was preliminary, it is suggested that further studies should be carried out to determine the extract's possible mechanism of action and whether the seeds extract could have a potential antidysglycaemic effect on pancreatic beta cells or other insulin-responsive tissues [9].

In another research, the hypoglycaemic effect of AnacardiumoccidentaleL. Methanolicfractionated extracts on Streptozotocin-induced diabetic rats was investigated bySokeng [2]. The effect of the methanolic leavesextract, dichloromethane, ethylacetate and $n$-hexane fractions from Anacardiumoccidentalewas investigated in streptozotocininduced diabetic rats. Oral administration of the methanol extract at doses of 35,175 and $250 \mathrm{mg} / \mathrm{kg}$ significantly reduced blood glucose levels in diabetic rats 3hours after administration. Of three different doses, maximum reduction of 37 and $35 \%$ in blood glucose levels was respectively observed with doses of 175 and $250 \mathrm{mg} / \mathrm{kg}$. When administered repeatedly, the blood glucose reducing effect of the methanol extract at the dose of $175 \mathrm{mg} / \mathrm{kg}$ in diabetic rats became more pronounced $(48 \%)$. Fractions from the methanol extract at the dose of $175 \mathrm{mg} / \mathrm{kg}$ also decreased the blood glucose levels in diabetic rats after repeated administration. The $\mathrm{n}$-hexane fraction produced the maximum hypoglycaemic effect (45\%) and the same dose of the dichloromethane and ethyl acetate fractions respectively reduced hyperglycaemia by 21 and $41 \%$ at the end of the treatment. On the other hand, a significant decrease in urine glucose levels was observed in diabetic rats after repeated administration of the methanol extract and fractions. These results suggest the hypoglycaemic effect of the methanol extract and fractions of $A$. occidentaleinstreptozotocin-induceddiabetic rats. Hexane and ethyl acetate fractions showed the most prominent actions suggesting thepresence of non-polar and polar hypoglycaemic compounds in the plant.From results obtained, it can be concluded that the regenerative effect of A.occidentaleextract on beta cells may be due to the phytochemical components of the herb. 
The hypoglycaemic effect of the aqueous leavesextract of $A$. occidentale used traditionallyfor the management of diabetic diseases was investigated using normoglycaemic albino rats. The leaves aqueous extract was found to contain phytochemicals such as alkaloids, saponins, flavonoids and tannins. The aqueous extract significantly lowered the blood

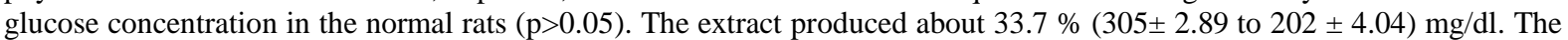
serum triglyceride decreases by $48.28 \%(435 \pm 4.50$ to $225 \pm 1.50) \mathrm{mg} / \mathrm{dl}$ in the experimental rats. While serum total protein decreases by $18.41 \%(27.7 \pm 2.54$ to $22.6 \pm 0.32) \mathrm{g} /$ day and weight increase was $4.75 \%(134.6 \pm 5.02$ to $128.5 \pm 1.15) \mathrm{g}$. The result obtained indicated that the extract has a moderate hypoglycaemic effect and may be used locally for the treatment ofdiabetes mellitus [10].

In a similar research, the antidiabetic activity of $A$. occidentale stem-bark methanolic extract was investigated in fructose-fed (diabetic) and normal rats. Animals were randomly divided into group A (control), group B (treated with $200.0 \mathrm{mg} / \mathrm{kg}$ body weight of the extract; orally), group C (fed with enriched fructose diet only, 25\%; w/w) and group D (fed with enriched fructose diet along with $200 \mathrm{mg} / \mathrm{kg}$ body weight of the extract; orally). Animals were treated with extract and=or enriched fructose diet for 21 days. The enriched fructose diet resulted in significant increases in plasma glucose, total cholesterol, triglyceride, total cholesterol= HDL-cholesterol ratio, malonyldialdehyde, total protein, urea, and creatinine. Administration of the extract significantly prevented changes in plasma glucose, triglyceride, total cholesterol=HDLcholesterol ratio, malonyldialdehyde, urea, and creatinine induced by enriched fructose diet. On the other hand, treatment with enriched fructose diet and=or extract did not have any significant effect onplasma alkaline phosphatase level. These results show that chronic oral administration of methanol extract ofA.occidentale stem-bark at a dose of $200 \mathrm{mg} / \mathrm{kg}$ body weight may be a safe alternative antihyperglycaemic agent that has beneficial effect by improving plasma glucose and lipids in fructose-induced diabetic rats, which is associated with a reduced lipid peroxidation [11].

\section{DISCUSSION}

Insulin synthesized by beta cells of the pancreas is the principal hormone that regulates uptake of glucose from the blood. Therefore, the deficiency of insulin or the insensitivity of its receptor or a combination thereof has been implicated in all forms of dysglycaemia. The increase in beta cell population in the experimental animal models indicates a regenerative role of natural antidiabetic candidates such as A.occidentaleleaves, seeds and stem barks extracts. Beta cells regeneration may be attributed to the presence of tannins, anacardic acid, phenol, flavonoids, alkaloids andsaponins present in the extracts have been documented to have antioxidant effects. The herb also contains amino acids which may have contributed to the formation of Journals of Botany, Agriculture and Healthcare [12].

In a previous study by Sokeng[2], the hypoglycaemicactivities of the aqueous leaves extract of $A$. occidentalein diabetic rats and its prophylactic activity against the diabetogenic action of streptozotocinhave been documented.The effect of the methanolicextract of A. occidentaleon the blood glucose levels in fasting diabetic rats was evaluated. Oral administration with doses of 35,175 and $250 \mathrm{mg} / \mathrm{kg}$ of the methanol extract exhibited a decrease in blood glucose levels of treated rats compared to control rats. Maximum reduction of 37 and $35 \%(p<0.001)$ in blood glucose levels was recorded 180 min after administration respectively, with doses of 175 and $250 \mathrm{mg} / \mathrm{kg}$. Blood glucose levels thereafter gradually increased the after administration of the extract. Repeated administration of the methanol extract of $A$. occidentaleto streptozotocin-induced diabetic ratssignificantly reduced the blood glucose levels in a dose-dependent manner when compared to untreated diabetic rats. The highest significant $(\mathrm{p}<0.001)$ hypoglycaemic effect $(48 \%)$ was observed with the dose of 175 $\mathrm{mg} / \mathrm{kg}$. On the other hand, the same dose of the extract significantly $(\mathrm{p}<0.01)$ decreased the urine glucose in diabetic treated rats compared to their control. Results obtained with diabetic rats treated with themethanolic extract $(175 \mathrm{mg} / \mathrm{kg})$ of $A$. occidentale prompted the study with fractions of this extract in view to determine the nature of active principles. Fractions from A. occidentaleat the dose of $175 \mathrm{mg} / \mathrm{kg}$ decreased the blood glucose levels in streptozotocin-induced diabetic rats after repeated administration for 3 days. The n-hexane fraction produced the maximum hypoglycaemic effect $(45 \%)$ and the same dose of the dichloromethane and ethyl acetate fractions reduced the hyperglycaemia by 21 and $41 \%$ at the end of the treatment. On the other hand, a significant decrease in urine glucose levels was observed in diabetic rats receiving plant fractions compared to untreated diabetic rats.

Streptozotocin-induced diabetes provides a condition of insulinopenia and has been described as a useful experimental model to evaluate the activity of hypoglycaemic agents [13]. In another study, a single administration of the methanol extract of A. occidentale effectively lowered the blood glucose level in streptozotocin-diabetic rats compared to their control. Streptozotocin selectively damages the pancreatic insulin secreting cells, leaving less active cells and resulting in a diabetic state [14]. Since the methanol extract of A. occidentalereduced the blood glucose significantly in streptozotocindiabetc rats it may be assumed that the diabetic state is not severe. Thus, the extract may act by a direct stimulation of insulin secretion in remaining alpha cells. This effect could be attributed to compounds like (-)-epicatechin[15], kampferol, quercetolrhamnosides[16] and alpha-sitosterol 3-â-D glucoside, present in A. occidentale, that have been reported to stimulate insulin secretion [17]. On the other hand, the action of the extract may involve insulin-like extra pancreatic mechanisms such as the stimulation of glucose utilisation and the reduction of hepatic gluconeogenesis [18], [19]. 
In a similar research, repeated administration of the methanol extract of $A$. occidentaleand its fractions showed hypoglycaemic effects as reflected by a decrease in blood and urine glucose levels. The dichloromethane fraction had a very low hypoglycaemic activity, whereas the direct, first n-hexane and subsequent ethyl acetate fractions were more active. This result suggests that at least two main types of hypoglycaemic compounds are present in the methanolic extract of A. occidentale: non-polar and polar compounds respectively soluble in n-hexane and ethyl acetate. Such observations have been reported by Niyonzima [20], with the stem bark extracts of Spathodeacampanulata. Moreover the hypoglycemic activity of the methanol extract of $A$. occidentalewas shown to be more pronounced in repeated treatment compared to the acute test. This plant extract may act by stimulating the revitalisation process in the residual pancreatic alphacells in treated animals. Also, an increase in alpha cells mass due to the proliferation or the anti-apoptosis process in the remnant islet was reported [21] after 4 days administration of a GLP-1 derivative in pancreatectomized rats. The retardation of membrane-bound alpha-glucosidase reaction and/or inhibition of passive glucose transport would successfully flatten the postprandial blood glucose excursions or reduce hyperglycaemia [22]. The presence of alpha-glucosidase inhibitors have already been reported in A. occidentale nut shell liquids [23]. Thus, the hypoglycaemic activity of $A$. occidentalemay also be attributed to the inhibition of alpha-glucosidase in the gastro-intestinal tract. Hence, it could be concluded that the methanol leaves extractand its fractions had hypoglycaemic effect in streptozotocin-induced diabetic rats. Hexane and ethyl acetate fractions showed the most prominent actions suggesting the presence of non polar and polar hypoglycaemic compounds in the plant.

Acute administration of aqueous ormethanol stem-bark extracts of cashew plant has been shown to have a hypoglycaemic effect in fasted streptozotocin-induced diabetic rats [24]. The study which was undertaken to validate the effect of chronic administration of an oral daily dose of methanol extract of $A$. occidentale stem-bark (200mg/kg body weight) on fasting blood glucose, lipid profile, and lipid peroxidation in fructose-fed and normal rats,portrayed that the hypoglycaemic effect of the administration ofmethanol plant extract at a single dose of $800 \mathrm{mg} / \mathrm{kg}$ body weight was found to be more pronounced than that of the aqueous extract in both the normal and streptozotocin-diabetic rats. The study also demonstrated that chronic administration of the extract $A$. occidentale causes a significantincrease in total plasma protein without significantly altering the plasma levels of urea and creatinine in normalrats. This finding indicates that the extract of A.occidentale could increase the rate of protein synthesis while renal function is preserved in normal rats.Enhanced protein synthesis seems to be associated withthe administration of $A$. occidentale and may probablybe attributed to the improvement in glycaemic control orinsulin secretion. In the fructose-fed diabetic rats, the increase blood glucose is accompanied by an increase in the plasma protein,urea, and creatinine levels. The treatment withA. occidentale led to reductions in plasma urea and creatininelevels toward the control values while the extractfailed to affect the total plasma protein levels in fructose-fed rats. These results suggest that the methanol extract of $A$. occidentale stem-bark may be able to prevent altered protein metabolism as well as impaired renal function in diabetes mellitus. In conclusion, the results of our current study demonstrate that chronic treatment with methanol extract of $A$. occidentale stem-bark at $200 \mathrm{mg} / \mathrm{kg}$ may be a safe agent that has a protective role against the diabetogenic and atherogenic effects of high-fructose diet by reducing the hyperglycemic, hyperlipidemia, as well as lipid peroxidation.

The phytochemicals are the prime and bioactive compounds of plants that are responsible for the extended biological properties. Innovative approaches to explore the biological properties exhibited by phytochemical candidate compounds present in the plant nut extracts would be helpful to reach the market and economy to a considerable extent.The extractants were tested for the presence of elementary phytochemicals like alkaloids, carbohydrates, flavonoids, phenolics, steroids, triterpenoids, volatile oils and xanthoproteins following standard methods. Preliminary Phytochemical analysis of A. occidentale extracts revealed an array of rich secondary metabolites such as tannins,terpenoids, alkaloids, flavonoids, phenols, steroids, glycosides and volatile oils. The ethanolic extracts of $A$. occidentalenuts result the presence of various phytochemicals compounds such as triterpenoids, phenolics and volatile oils. Ethyl acetate extracts exhibited a different combination of phytochemicals, phenolics, volatile oils, xanthoprotein and carbohydrates. Acetone found to be effective in dissolving the phytochemicals since many different compounds like triterpenoids, phenolics, volatile oils, flavonoids, xanthoprotein and carbohydrates. However, Acetone, acted as good solvent for flavonoids extraction. The obtained results are in accordance with the reports of Tedong[25], that the phytochemical analysis of $A$. occidentale $L$. revealed the presence of alkaloids, polyphenols and saponins. 
Plants with hypoglycaemic andantihyperglycaemic activities may contain one or morechemical constituents [26]. Classes of chemical compounds isolated from plants are documented to have the potential to decrease the blood glucose level [27]. Thus,the significant antidiabetic effect of extracts of A.occidentalecould be due to the possible presence of the aforementioned constituents in the part of the plant used in this particular study, which could act synergistically or independently, enhancing the activity of glycolytic and glyconeogenic enzymes.The present results of aqueous leaves extract of A.occidentalegrown in Nigeria examined for its effecton blood glucose correlates with the work done byTanko[28], while serum total protein, serum triglycerideand the body weight in normoglycemic rats displayedsome remarkable differences. This shows thatthe plant $A$. occidentalecontains chemicalcompounds like alkaloids, saponins, flavonoids andtannins which in agreement with previous report[29]. Based on the increasing number of reports on blood glucose reduction by some saponins[29] and alkaloids[30] isolated from other medicinalplants, it is likely that the bioactive principles could bepresent in one or more of the phytochemical candidate moieties.It is suggested that these compounds stimulate influx of $\mathrm{Na}^{+}$and $\mathrm{Ca}^{2+}$ ions by inhibiting the $\mathrm{Na}^{+}-\mathrm{Ca}^{2+}$ exchanger therebystimulating the influx of $\mathrm{Ca}^{2+}$ into the innermembrane, leading to membrane depolarization. This activates the synthesis of ATP through oxidativephosphorylation. This mechanism feeds forwardglucose, stimulating insulin secretion. The ATP produced mediates the secretion of insulin by insulinsecretagogues. From the results obtained, it could be concluded that the regenerative effect of Anacardiumoccidentaleextract on beta cells may be due to the phytochemical components of the herb.

\section{CONCLUSION}

The various fractionated leaves, seeds, and stem bark extracts of A.occidentale (cashew) were investigated for the phytochemical and anti-hyperglycaemic properties and the results obtained from this research portrayed that the leaves, seeds as well as the stem barks extracts of A. occidentalecould be a lead candidate for the synthesis of potent antidiabetics or it could be used directly as a nutraceutical for the management of chronic dysglycaemia, which has posed a new threat to the global health security. Although this is a preliminary study, it is suggested that further studiesbe carried out to ascertain whether theA.occidentale extracts could have a potential anti-dysglycaemic effect on pancreatic beta cells or other insulin-responsive tissues. Also, investigational studies on the safety profile as well as the possible mechanisms of action of plantbased hypoglycaemics should be carried out.

\section{REFERENCES}

[1.] Tiwari A.K. and Rao, J.M. (2002).Diabetes mellitus and Multiple Therapeutic Approaches of Phytochemicals- Present Status and Future Prospects.Current Sci., 83.30-38.

[2.] Sokeng, D.S., Kamtchouing, P., Watcho, P., Jatsa,H.B., Moundipa, P.F., Ngounou, F.N., Lontsi, D.,Bopelet, (2001).Hypoglycémic activity ofAnacardiumoccidentaleL. Aqueous extract innormal and streptozotocin-induced diabetic rats.Diabetes Res. 36: 001-009.

[3.] http//www.anniesremedy.com/herb_detail418.php. Accessed on July 6, 2013.

[4.] Kubo J. (1999). Anti-Helicobacter pyloriAgents From the Cashew Apple.J. Agric. Food Chem. 47.533-537.

[5.] Akinpelu D.A.(2001). Antimicrobial Activity of AnacardiumoccidentaleBark.Fitoterapia 72.

[6.] Sobrevia L, Mann G.E. (1997). Dysfunction of Endothelial Nitric oxide Signaling Pathway in Diabetes and Hyperglycaemia. ExpPhysio 82. 423-454

[7.] Abbott A.D., Brand F.N., Kannel W.B. (1990). Epidemiology of some Peripheral Arterial Findings in Diabetic Men and Women- Experiences from the Framingham Study. Am J Med 88. 376-381.

[8.] Kamtchouing, P., Sokeng, D.S., Moundipa, P.F.,Pierre, W., Jatsa, B.H. and Lontsi, D. (1998).Protective role of Anacardiumoccidentale extractagainststreptozotocin-induced diabetes in rats.J. Ethnopharmacol., 62: 95-99.

[9.] Tedong, L. Dimo, T., Dzeufiet, P.D.D., Asongalem,A.E., Sokeng, D.S., Callard, P., Flejou, $\quad$ J.F. andKamtchouing, P. (2006).Antihyperglycemic and renalprotective activities of Anacardiumoccidentale(Anacardiaceae) leaves in streptozotocininduceddiabetic rats. Afr. J. Trad.CAM., 3 (1): 23 - 35

[10.] Saidu, A. N., Mann, A., Balogun, S. (2012). The Hypoglycemic Effect of Aqueous Extract of the Anacardiumoccidentale Linn Leaves Grown in Nigeria on Normoglycemic Albino Rats.Journal of Emerging Trends in Engineering and Applied Sciences (JETEAS), 3(2):302-308.

[11.] Olatunji L.A., Okwusidi J.I., and Soladoye A.O. (2005).Antidiabetic Effect of Anacardium in Fructose-Diabetic Rats.Journal of Pharmaceutical Biology. 7. 589-593.

[12.] Mota, M.L.. Thomas, G., Barbosa, Filho J.M. (1985).Anti-inflammatory actions of tannins fromthe bark of AnacardiumoccidentaleL. J. Ethnopharmacol., 13 (3): 289- 300.

[13.] Bailey, C.J. and P.R. Flatt, (1986).Animal modelsof diabetes. In: Nattras M. [Ed.], Recent Advancesin Diabetes II. Churchill Livingstone, Edinburg,UK, pp: 71-89.

[14.] Junod, A., A.E. Lambert, W. Stauffacher and A.E.Renold, (1969). Diabetogenic action of streptozotocin: Relationship of dose to metabolicresponse. J. Clin. Invest.,48: 2129-2139.

[15.] Swarnalakshmi, T., K. Gomathi, N. Sulochana,E.A. Baskar, and N.S. Parmar, (1981).Anti- $\quad$ inflammatory activity of (-)epicatechin, abiflavonoid isolated from Anacardium occidentale Linn. Indian J. Pharm. Sc., 43: 205-208.

[16.] Arya, R., V. Babu, M. Liyas and K.T. Nasim,(1989). Phytochemical examination of the leaves ofAnacardiumoccidentale.J. Indian Chem. Soc.,66: 67-68.

[17.] Ivorra, M.D., Paya, M. and Villa, A. (1988).Hypoglycaemic and insulin Release Effect of Tormentric acid: A New Hypoglycaemic NaturalProduct. Planta Med, 54: 282-286. 
[18.] Ali, L., A.K. Azad Khan, M.I.R. Mamun.M. Mosihuzzaman., N. Nahar, M. Nur-e-Alam and

B. Rokeya, (1993). Studies on the hypoglycemiceffects of fruit pulp, seed and whole plant ofMomordicacharantiaon normal and diabeticmodelrats.PlantaMedica, 59: $\quad$ 408-412.

[19.] Gray A.M., Y.H.A. Abdel-Wahab and P.R. Flatt,(2000). The traditional plant treatment, Sambucusnigra(elder), Exhibits sulinLike andInsulin-releasing actions in vitro. J. Nutr., 130: 15-20.

[20.] Niyonzima G., G. Laekman, M. Witvorouw, B.VanPoel, L. Pieters, D. Paper, E. De Clerq, G. Franz and A.J. Vlietinck, (1999). Hypoglycemic, anticomplement and anti-HIV activities ofSpathodeacampanulatastembark.Phytomedicine, 6: 45-49.

[21.] Rømer J., E. Bentsen, J. Damgaard, B. Jorgensen,K.E. Pedersen, P. Rothe, L.B. Knudsen, K. Wassermann and U. Ridel, (2001). Effect of thelong-acting GLP-1 derivative NN2211 in 60\%pancreatectomized rats. Diabetologia, 44: A197.

[22.] Toeller M., (1994). alpha-glucosidase inhibitors indiabetes: efficacy in NIDDM subjects. Eur. J. Clin. Invest., 24: 31-35.

[23.] Toyomizu M., S. Sugiyama, R.L. Jin andT. Nakatsu, (1993).á-glucosidase and aldosereductaseinhibitors : constituents of cashew,Anacardiumoccidentale, nut shell liquids.Phytother. Res., 7: 252-254.

[24.] Ojewole JA (2003): Laboratory evaluation of the hypoglycemiceffect of Anacardiumoccidentale Linn (Anacardiaceae)stem-bark extracts in rats. Methods Find ExpClinPharmacol 25: 199-204.

[25.] Tedong L., Madiraju P., Martineau L.C., Vallerand D., Arnason J.T., Dzeufiet D.P., Lavoie $\quad$ L., Kamtchouing P., and Haddad P.S., (2010). Hydro-ethanolic Extract of AnacardiumoccidentaleNut and its Principal compound, anacardic acid, Stimulate Glucose Uptake in C2C12 Muscle Cells. Mol. Nutr. Food Res. 54.1-10.

[26.] Gupta, R., Bajpai, G.K., Johri, S. and Saxena, A.M.(2008). An Overview of Indian NovelTraditionalMedicinal Plants with AntidiabeticPotentials.Afr. J. Trad. CAM, 5 (1): 1 - 17.

[27.] Raghavan, B. and Krishnakumari, S. (2006). Effect ofTerminaliaArjunaStem Bark on Antioxidant statusin Liver and Kidney of Alloxan Diabetic Rats.Indian J. Physiol.Pharmacol., 50 (2): 133-142.

[28.] Tanko, Y., Abdelaziz, M.M., Adelaiye, A.B., Fatihu,M.Y., Musa, K.Y. (2008). Effects of Hydromethanolicleaves extract of Indigoferapulchraon blood glucoselevels of normoglycemic and alloxan-induceddiabeticWistar rats. Internat. J. Applied Res. Nat.Prod., 1(4): 13-18.

[29.] Dietewa, M., Samba, B.C., Assah, H.C.T. and Abena,A.A. (2004).Hypoglyceamic and antihyglycemiceffects of diethyl ether fraction isolated from theaqueous extract of the leaves of CogniauxiapodoleanaBaillon in normal and alloxaninduceddiabeticrats. J. Ethnopharmacol. 92: 229-232.

[30.] Dietewa, M., Samba, B.C., Assah, H.C.T. and Abena,A.A. (2004).Hypoglyceamic and antihyglycemiceffects of diethyl ether fraction isolated from theaqueous extract of the leaves of CogniauxiapodoleanaBaillon in normal and alloxaninduceddiabeticrats. J. Ethnopharmacol. 92: 229-232. 